\title{
A HUMANIZAÇÃO EM PAULO FREIRE E SUAS RELAÇÕES COM A EDUCAÇÃO PREVENTIVA INTEGRAL
}

\author{
TAtiane DeluRdes de LIMA-Berton \\ Michelle Popenga Geraim Monteiro \\ ArACI AsInELLI-LUZ \\ Universidade Federal do Paraná (UFPR), Curitiba, Paraná, Brasil
}

\begin{abstract}
Resumo: Paulo Freire, embora não esteja mais presente fisicamente, ainda é um autor atual e referência em muitas pesquisas e estudos educacionais. Seus escritos inspiram esperança e liberdade para muitos educadores, pois os valores defendidos por ele podem facilmente ser apropriados e aplicados a uma educação humanista, que foca no ser humano, assim como à Educação Preventiva Integral. Por isso, este estudo busca compreender as principais contribuições freirianas para a prática da Educação Preventiva Integral. Trata-se de um estudo qualitativo, de cunho teórico, com base em obras de Paulo Freire $(1993,1996,1999)$ e na Educação Preventiva Integral (ASINELLI-LUZ, 2014; LIMA, 2017; LIMA; MONTEIRO; ASINELLI-LUZ, 2019), no qual se discute como as práticas educativas humanistas podem contribuir para o processo de prevenção das violências e desigualdades que atingem o ser humano, uma vez que se valoriza o ser e o seu processo de desenvolvimento como um todo.
\end{abstract}

Palavras-chave: Educação. Educação Preventiva Integral. Humanização.

INTRODUÇÃO

Os estudos freirianos continuam sendo objeto de debates e discussões no mundo todo. Paulo Freire, educador e filósofo brasileiro, desenvolveu reflexões bem pertinentes sobre a Educação, nas quais se destaca a importância de aprender de maneira humanizadora, em uma relação entre o educador e o educando. Freire é um educador que sensibiliza e reforça, no campo da educação, as noções de uma pedagogia crítica que se funda em uma educação transformadora, com base na paz, ética, emancipação política, justiça social, estética, diálogo e respeito, a partir da formação do estudante pensante e crítico. Ele apresentava suas reflexões, como a teoria do conhecimento (FREIRE, 1999), como um processo consciente de aprender e ensinar, no qual o educando assimila, constrói, reconstrói e socializa seu conhecimento. Porém, o autor não considerava isso como uma metodologia ou método de ensino.

Com base em uma educação popular, Freire $(1996,1999)$ quebrou as barreiras da metodologia tradicionalista e elitista, demonstrando um comprometimento maior com o envolvimento, com a relação entre os seres humanos. Nesses estudos, que 
apresentam contextos e situações de exclusão, massificação, preconceito, falta de estímulo, o autor provoca discussões que promovem o processo de conscientização de uma sociedade democrática. Oportuniza ainda reflexões sobre o incentivo aos interesses individuais e, principalmente, aos coletivos que despertam a vontade de aprender pelo fato de se proporcionar novas possibilidades de aprendizagem. Ademais, ressalta a importância de uma educação humanista, crítica, desveladora, ética e totalizante, "que integre a leitura de mundo e a leitura da palavra, a fim de que possamos nos preparar para o enfrentamento das ideologias, das lutas de classe e das formas de dominação" (PAULA; MELLO, 2016, p. 81).

A relação eu (nós) e o mundo aponta para um traço essencial do que entendemos por educação. A educação funda-se na essência humana sempre em formação. A formação do ser humano, de sua subjetividade correlata a objetividades (segundo a fenomenologia), acontece em um fluxo contínuo da vida e das potencialidades humanas. Envolve a experiência própria, a experiência com os outros e a mediação de horizontes proporcionados pelo mundo (JOSGRILBERG, 2013, p. 21).

Freire (1996), ao longo da sua militância educacional, nunca deixou de lutar pela superação das desigualdades sociais e contra a opressão, pois seus projetos envolviam o desenvolvimento da consciência crítica por meio da construção histórica. Desse modo, as bases se constituíam de acordo com a relação educando e educador, do respeito mútuo, da autonomia e da dialogicidade, que foram transformados em princípios metodológicos. Sabendo que a palavra 'método' pode significar seguir passos para chegar a um fim, Freire, em entrevista a Nilcéia Lemos Pelandré, em abril de 1993, destaca que esse termo não retrata com fidelidade sua ideia e seu trabalho.

Eu preferia dizer que não tenho método. O que eu tinha, quando muito jovem, há 30 anos ou 40 anos, não importa o tempo, era a curiosidade de um lado e o compromisso político do outro, em face dos renegados, dos negados, dos proibidos de ler a palavra, relendo o mundo. O que eu tentei fazer e continuo hoje, foi ter uma compreensão que eu chamaria de crítica ou de dialética da prática educativa, dentro da qual, necessariamente, há certa metodologia, um certo método, que eu prefiro dizer que é método de conhecer e não um método de ensinar (FEITOSA, 1999, p. 49).

Contudo, a expressão "Método Paulo Freire" tornou-se conhecida universalmente como uma referência de concepção democrática e radical da prática educativa. Assim, enquadradas como teorias do conhecimento, as ideias de Freire se expandiram pelo mundo, tornando-se fonte de inspiração para muitos educadores, especialmente pela possibilidade inovadora de despertar a consciência e de unir as pessoas numa sociedade igualitária e voltada para a justiça (LIROLA, 2019). Por isso, hoje 
Freire é considerado um dos autores mais lidos de todos os tempos, sendo uma referência em muitas instituições de ensino.

Partindo da compreensão da educação como humanizadora, capaz de promover a transformação social na relação "educador e educando", em todas as modalidades de ensino e espaços educativos - escolares e não escolares -, o presente artigo tem como pergunta norteadora: "Quais são as contribuições da teoria humanista de Paulo Freire para a Educação Preventiva Integral?" Para respondê-la, o objetivo geral do estudo é compreender quais são as principais contribuições freirianas para a prática da Educação Preventiva Integral.

O estudo qualitativo, de cunho teórico, foi o caminho metodológico desta pesquisa. Foram escolhidas três obras de Paulo Freire (Professora sim, tia não, 1993; Pedagogia da autonomia, 1996; Educação como prática de liberdade, 1999) por se aproximarem das temáticas de autonomia, liberdade e prática docente, corroborando a perspectiva da Educação Preventiva Integral, proposta por Asinelli-Luz (2014), Lima (2017) e Lima, Monteiro e Asinelli Luz (2019). Realizou-se, nessa perspectiva, uma discussão sobre as aproximações entre esses estudos.

A Educação Preventiva Integral é uma abordagem educativa que visa promover atos de prevenção que possam atrasar ou até mesmo evitar um dano ou problema aos sujeitos envolvidos. Isso porque, ao atuar na garantia de direitos, na compreensão das fragilidades e potencialidades de cada educando, dá a oportunidade de compreender os seus anseios, medos, angústias, conflitos e de sensibilizá-lo para que crie uma consciência de seus atos e para que possa superar suas demandas. É uma prática utilizada para prevenção do abuso de drogas, bullying e outras violências que comprometem o desenvolvimento humano, em todas as fases de vida.

Constituída por meio de experiências e suporte teórico em Paulo Freire e outros autores (Urie Bronfenbrenner, Edgar Morin, Celestin Freinet), a Educação Preventiva pode ser aplicada em espaços de salas de aula escolares ou não escolares. Um exemplo é a prevenção do abuso de drogas. A Universidade Federal do Paraná (UFPR) ofereceu uma disciplina eletiva denominada "Métodos e Técnicas educacionais de prevenção do abuso de drogas", entre os anos de 1996 a 2016. Além de ser uma disciplina eletiva, ela também contemplava um projeto de extensão: "A prevenção como princípio para o enfrentamento do abuso de drogas".

Pautada no diálogo, nos temas geradores, na problematização da vida, a Educação Preventiva Integral é baseada em Paulo Freire, em teorias da Complexidade (MORIN, 2000), da Bioecologia do Desenvolvimento Humano (BRONFENBRENNER, 2011), de teóricos da Pedagogia Social e de outras fontes que estudam relações sociais e o desenvolvimento humano. Para se garantir sua efetividade, são necessários multiprofissionais que visem à mediação horizontal entre educador e educando, oportunizando a interação e a troca de vivências. Assim, possibilita-se conhecer melhor o educando, suas histórias, suas vivências, suas demandas, potencialidades, a fim de atuar preventivamente para que o problema não se instaure. Para os autores,

[...] a Educação Preventiva Integral contempla o desenvolvimento pleno do ser humano, para que promova seu crescimento, tanto individual, quanto coletivo. Como incentivo ao diálogo, troca de 


\begin{abstract}
experiências e interações sociais, permite o alcance da compreensão do papel cidadão no mundo, da consciência da trajetória de vida, da projeção do futuro, da contribuição para a vida em sociedade e da conscientização da posse de particularidades, funções, intencionalidades e ações transformadoras. É preciso conhecer o sujeito e atuar antecipadamente ao problema (LIMA; MONTEIRO; ASINELLI-LUZ, 2019, p. 12).
\end{abstract}

A Educação Preventiva Integral se aproxima da teoria do conhecimento, de Freire, que investiga o universo dos educandos por meio de temas geradores, ou seja, parte do estudo da realidade (fala do educando) e da organização dos dados (fala do educador), permitindo que sejam extraídos dessas discussões os possíveis assuntos a serem trabalhados. Assim, os conteúdos de ensino são resultados de uma metodologia que parte do diálogo, em que cada sujeito, cada grupo envolvido no processo, irá inserir os temas necessários que fazem parte da sua rotina.

A educação não se restringe a conceitos científicos e técnicos, pois vai além dessas considerações. Quem atua nessa área, precisa ter a clareza de que, se relacionando com pessoas, o trabalho será muito mais complexo, pois não estará lidando com máquinas, e sim com seres pensantes e ativos. Assim, além da formação técnica, exigirá um envolvimento comprometido e afetivo, em que o educador precisará estar disposto a lidar com o desconhecido. Todos os seres humanos são capazes de discutir, refletir, produzir novos valores, desenvolver habilidades, tendo em vista as diferenças, as necessidades e as formas diversas de caminhar rumo ao crescimento do grupo social. A educação, nos espaços escolares e também nos não escolares, oferece a oportunidade de estimular a interação social, o diálogo e a reflexão sobre demandas individuais e coletivas, trabalhando na superação de vulnerabilidades e riscos sociais. É um andar coletivo que antecipa problemas antes que ocorram, que previne violências e injustiças sociais (LIROLA, 2019).

O que importa, nesse caso, não é transmitir conteúdos específicos, mas despertar novas formas de relações, de acordo com as experiências, com o que realmente é relevante e com o que será bem aproveitado pelos educandos. A ideia de transmissão de conteúdos está fora do contexto social dos sujeitos, compreendida como um "depósito de informações" ou uma "invasão cultural", pois, ao explicar um conteúdo, o educador, sem fazer relações com o cotidiano, não conseguirá atingir o saber popular que, dessa maneira, tornar-se-ia sem valor ao educando. Assim, um dos fatores mais importantes nesse processo é conhecer bem o educando, pois ele precisa se relacionar com o conhecimento a ser explorado.

As investigações dos temas geradores devem acontecer por meio de diálogos, para que haja uma educação libertadora de fato. Trata-se da intensa relação entre o educador e o educando, a fim de refletir sobre sua história, suas vivências, problemáticas e contextos de interação. Há uma aproximação na relação, em que, por ser dialógica, torna-se problematizadora e dessa forma permite que se obtenha um desenvolvimento maior da consciência dos sujeitos sobre os temas a serem trabalhados, uma vez que, 
investigando seu próprio universo, a atenção e admiração serão maiores, a fim de oportunizar a criticidade e as transformações (FREIRE, 1999).

\title{
A VISÃO HUMANISTA DA EDUCAÇÃO SOB A ÓTICA DE PAULO FREIRE E A EDUCAÇÃO PREVENTIVA INTEGRAL
}

A Educação, em um sentido bem amplo, cumpre uma função de socialização na vida humana desde que o homem passou a elaborar mecanismos para sua sobrevivência e começou a transmiti-los a outras gerações. Neste sentido, o processo educativo passou a humanizar o homem por meio de muitos mecanismos, sendo um deles a escola, cuja função é oportunizar conhecimentos para o desenvolvimento humano e a vida em sociedade.

A escola, por sua vez, deve desenvolver esse processo de socialização, garantindo "a reprodução social e cultural como requisito para a sobrevivência mesma da sociedade" (PÉREZ GÓMEZ, 1998, p. 14). Entretanto, essa tendência de reprodução acaba por se chocar com a tendência que busca mudar as concepções sociais existentes no mundo atual. Assim, nesse processo complexo dentro das escolas, de socialização do ser humano, há duas funções básicas e prioritárias das instituições escolares: a primeira delas é a incorporação no mundo do trabalho e a segunda é a formação do cidadão para sua intervenção na vida pública. Diante disso, o autor afirma haver uma contradição dessas duas funções em relação à sociedade.

\begin{abstract}
Neste sentido a socialização, a escola transmite e consolida, algumas vezes de forma explicita e em outras implicitamente, uma ideologia cujos valores são o individualismo, a competitividade e a falta de solidariedade, a igualdade formal de oportunidades e a desigualdade "natural" de resultados em função de capacidades e esforços individuais. Assume-se a ideia de que a escola é igual para todos e de que, portanto, cada um chega onde suas capacidades e seu trabalho pessoal lhes permitem. Impõe-se a ideologia aparentemente contraditória do individualismo e do conformismo social (PÉREZ GÓMEZ, 1998, p. 16).
\end{abstract}

A escola, nesse sentido, acaba sendo arbitrária e de certa forma prepara o cidadão para aceitar e adaptar-se às condições de competitividade, vendo essa situação como natural pelo processo de imposição da ideologia dominante na comunidade social, por meio do processo de transmissão de ideias e conteúdos pré-estabelecidos de aprendizagem. Entretanto, Pérez Gómez (1998) diz que esse processo de socialização dentro das escolas não é um processo linear, pelo contrário, é um cenário de profundas contradições e interações de valores, ideias e interesses diferentes entre os indivíduos. Por isso, muitas vezes, essas tendências reprodutoras da sociedade atual nem sempre são aceitas pelos sujeitos/alunos.

Assim, o processo de socialização acontece sempre através de um complicado e ativo movimento de negociação em que as reações e resistências de professores/as e alunos/as como indivíduos ou como 
grupos podem chegar a provocar a recusa e ineficiência das tendências reprodutoras da instituição escolar (PÉREZ GÓMEZ, 1998, p. 19).

Diante disso, o autor afirma que essa interação entre indivíduos acaba por gerar correntes que impulsionam mudanças, promovendo a transformação da condição humana de forma única dentro das escolas, chamada pelo autor de função educativa. Essa função, por sua vez, ultrapassa a função reprodutora da sociedade, apoiando-se no conhecimento social e historicamente construído, como forma de compreender a sociedade e quebrar a ideologia dominante.

Dessa forma, as inevitáveis e legítimas influências que a comunidade exerce sobre a escola e sobre o processo de socialização sistemática das novas gerações devem sofrer a mediação crítica da utilização do conhecimento, em virtude de suas exigências e necessidades econômicas, políticas e sociais (PÉREZ GÓMEZ, 1998, p. 22).

Por isso, a escola, como instituição social, tem o grande desafio de cumprir a função compensatória, ou seja, de equilibrar as diferenças existentes em uma sociedade capitalista, oferecendo oportunidades e possibilidades a todos os cidadãos de acesso à cultura e de enriquecimento de conhecimentos por meio da educação. A escola precisa atenuar os efeitos da desigualdade social pelo acesso ao conhecimento, através de um modelo didático flexível e plural (FREIRE, 1996). Portanto, para uma educação humanizadora, Paulo Freire, em seu livro Pedagogia da Autonomia (FREIRE, 1996), destaca a importância de uma leitura de mundo transformadora, levando os sujeitos ao pensamento crítico e emancipador. Ademais, "a Educação, em sua própria dimensão mais profunda, tem por missão a humanização a partir de uma ética fundamental, a vida humana em seus vários sentidos" (SALLES; FRASSON, 2019, p. 144). Apontando dessa forma para necessidade do processo reflexivo que deve estar presente no desenvolvimento humano, nas práticas diárias, assim como na formação do educando e do docente. Palavras como humanidade, esperança e simplicidade são peças chaves na educação igualitária e transformadora que Freire apresenta.

Paulo Freire ainda pode ser interpretado a partir de sua relação com a perspectiva do oprimido, dentro de uma educação pautada nos princípios de transformação e justiça social. O oprimido (FREIRE, 1987) é caracterizado pelo indivíduo que é excluído, que busca o protagonismo e anseia por mudanças sociais. Em meio a um contexto social marcado pela opressão das desigualdades e vulnerabilidades sociais relacionadas às condições históricas, Freire ressalta a relevância da criação/recriação de uma cultura a partir da transformação social. A luta pela liberdade, que vem pelo educar, concretiza-se a partir do momento que o sujeito toma consciência de sua condição de oprimido e se constrói socialmente por meio da criticidade e formação cidadã. A Pedagogia do Oprimido é caracterizada a partir da elucidação do sujeito à leitura de 
mundo, empoderando-o a partir da palavra que emancipa e da sua consciência como ser humano. Desse modo, é essencial que a educação abarque a coletividade.

\begin{abstract}
A ideia freireana de ler o mundo é fundamental para entender sua pedagogia: trata-se de ler os mundos nos quais se educam com interação de diferentes mundos. Os mundos em que vivemos formam diferentes campos semânticos em que os significados expressos são interpretados. Falar para pessoas propondo-lhes um mundo que the é alheio resulta, frequentemente, em um processo de colonização da mente (JOSGRILBERG, 2013, p. 35).
\end{abstract}

A educação humanista é baseada na tolerância, tendo o educador como um mediador do processo educativo social. Dialoga sobre a história, as potencialidades, conflitos, as desigualdades e as experiências vividas pelos educandos, oportunizando seu entendimento sobre o mundo e no seu inacabamento como ser humano. E essa ideia do ser humano inacabado impulsiona os sujeitos a buscarem novos aprendizados e conhecimentos numa ação constante de melhoria da formação humana, explorando a autonomia, mudança de seus contextos e vivências, obtendo maior consciência de si e dos espaços onde está inserido. A educação humanista auxilia na prática de valores, enfatizando o desenvolvimento humano e seus saberes construídos. Também constrói a cidadania, cidadãos que futuramente serão capazes de agir socialmente, de transformar a realidade social, viver de forma harmônica no respeito às diversas culturas e saberes (FREIRE, 1996).

O educador e o educando exercem funções horizontais, pois, juntos estabelecem ações do conhecimento, exercendo o equilíbrio entre autoridade e liberdade, na qual viabiliza a prática do diálogo e da troca de saberes por meio da consciência, criticidade e autonomia. A partilha entre educando e educador precisa ser um ato de recriação e re-significação de significados, pois a libertação não ocorre apenas no campo cognitivo, mas também acontece, principalmente, nos campos políticos e sociais (FREIRE, 1999). A Educação, assim, "não é mera transmissão de um conjunto de conhecimentos acumulados pela humanidade, mas encontro permanente entre seres humanos, mediado pelos diversos saberes que todos possuem, educadores e educandos" (CUPOLILLO, 2007, p. 53).

O educando é desafiado a refletir sobre o seu papel na sociedade, a repensar a sua história enquanto aprende a decodificar os símbolos que the são lançados, promovendo, nessa perspectiva, a superação da consciência ingênua (conhecida também como consciência mágica) e passa para a consciência crítica e transformadora. Essa perspectiva, salientada por Freire (1999), é também defendida na Educação Preventiva Integral, em que se trabalha com o educando, com foco em sua história, sua realidade, sua cultura, bem como em suas relações. A intenção da prevenção é a atuação através das necessidades e potencialidades do sujeito por meio da educação, promovendo referências criativas, solidárias e construtivas. O foco está no sujeito, no modo que obtém consciência das suas potencialidades e dificuldades, como constrói e fortalece suas relações, provocando discussões sobre as diversas dimensões do sujeito - 
biopsicossocial (ASINELLI-LUZ, 2014; LIMA, 2017; LIMA; MONTEIRO; ASINELLI-LUZ, 2019; CUPOLILLO, 2007).

É um conjunto de valores, atitudes, ações, que uma comunidade adota, baseada em sua história, e no conhecimento científico, para se antecipar aos problemas, num esforço para evitar a ocorrência de fatos indesejáveis, reduzir a incidência ou o índice de ocorrência de novos casos, usando estratégias educacionais para a valorização do ser humano (ASINELLI-LUZ, 2014, p. 394).

Desse modo, é necessário que as ações preventivas sejam o ponto de partida para o desenvolvimento individual e coletivo, favorecendo uma discussão e uma reflexão sobre os aspectos que envolvam a consciência crítica sobre valores, diversidade e outras esferas da sociedade, antecipando, assim, a compreensão do sujeito e de suas problemáticas para o enfrentamento de dificuldades, bem como para o investimento no coletivo por meio da cidadania, da igualdade e da justiça social. A prevenção, nesse caso, tem o sentido de amparar o indivíduo dentro de sua história, contexto e necessidades, permitindo que se torne autor diante dos desafios e enfrentamentos cotidianos.

Como práticas educativas, as salas de aula e os ambientes de convivência precisam estar dispostos a abrir espaço para fóruns de debates, chamados de Círculos de Cultura, em que a interação possibilita, não apenas a construção de conhecimentos, mas, principalmente, a consciência da própria história. Isso ocorre porque os educandos possuem a abertura para discutir sobre fatos de suas vidas, com a oportunidade de reconstrução da história, na qual são desafiados a se perceberem protagonistas dela. Ao dialogar com o coletivo e com o próprio educador sobre seu meio e sua realidade, eles têm a oportunidade de descobrir novos saberes e novos valores contidos em sua prática, que antes passavam desapercebidos (LIMA, 2017). Reafirma-se, dessa forma, a importância das reflexões éticas e críticas na educação, a busca pelos direitos e o respeito entre os seres humanos e o anseio pela mudança, que transforma o eu para o coletivo, a partir de um olhar pedagógico humanizador, de acordo com a sua realidade social. É uma visão esperançosa de um caminho para emancipar os oprimidos.

Para a construção de reflexões no processo educativo, o educando deverá ser mediado e estimulado pelo educador a estar à frente das discussões como protagonista. Precisa compreender as condições em que está inserido, o que o levará à busca da intervenção para a transformação. E nessa perspectiva, Freire (1999), à luz da Pedagogia Social, sensibilizava sobre a importância das construções individuais (de consciência de si) e das sociais, que fazem parte das práticas metodológicas da Educação Preventiva Integral (LIMA, 2017; LIMA; MONTEIRO; ASINELLI-LUZ, 2019). Portanto, pode-se dizer que as discussões que envolvem a educação transformadora de Paulo Freire contribuem significativamente para o aprofundamento dos conceitos estabelecidos pela Educação Preventiva Integral, de compreensão do sujeito histórico e protagonista, e da relevância das suas relações para seu crescimento como ser social, político e cultural. 
LIMA-BERTON, T. D. de; MONTEIRO, M. P. G.; ASINELLI-LUZ, A.

\begin{abstract}
Só na medida em que o educando se torne sujeito cognoscente e se assuma como tal, tanto quanto sujeito cognoscente é também o professor, é possível ao educando tornar-se sujeito produtor da significação ou do conhecimento do objeto. É neste movimento dialético que ensinar e aprender vão se tornando conhecer e reconhecer. $O$ educando vai conhecendo o ainda não conhecido e o educador reconhecendo, o antes sabido (FREIRE, 1993, p. 119).
\end{abstract}

O educador, por sua vez, possui o papel fundamental de contrariar a visão tradicionalista, tornando-se, então, um verdadeiro "animador de debates", um facilitador. Ou seja, ele possui o papel de mediar o debate, problematizar discussões, conhecer o universo vocabular do educando, seu saber advindo da oralidade, reinterpretar sua bagagem cultural, realizar parcerias, atribuindo ao educando um papel de protagonista, atuando como agente de transformação de sua própria história e do ambiente que o cerca (FEITOSA, 1999; FREIRE, 1999; LIMA, 2017).

Freire (1993) destaca a dialogicidade do ato educativo, na qual destaca a Educação pela prática e consciência pelas transformações sociais. O diálogo, assim como era para Freire (1993), também é base e fator importante para a interação entre educador e educando na Educação Preventiva Integral (ASINELLI-LUZ, 2014; LIMA, 2017; LIMA; MONTEIRO; ASINELLI-LUZ, 2019).), uma vez que há o objetivo de promover a ampliação da visão de mundo, mediante a conversa, a interação. O diálogo torna-se um fator fundamental para todo o processo. Na busca pela justiça social, pela sua compreensão dentro dos contextos da sociedade, é necessário refletir sobre as demandas e potencialidades de cada sujeito. Compreender valores, culturas, realidades fazem com que o sujeito compreenda os processos de construção da sociedade, da cidadania e da democracia (LIROLA, 2019).

Feitosa (1999) ainda complementa que o diálogo é uma ação de amor, humildade e fé nos homens, depositando a confiança no seu poder de criar, recriar, fazer e refazer. Nessa perspectiva, a dialogicidade (FREIRE, 1993) está relacionada às chamadas "categorias gnosiológicas", nas quais se destaca o trio: educador-educando-objeto de conhecimento, sendo eles indissociáveis, pois se acredita que esta justaposição se realiza como atitude democrática, libertadora, conscientizadora e dialógica. Dialogar requer esforço, atenção e dedicação do professor, do educador social. É um canal de exploração de percepções, pensamentos e novas perspectivas. Diálogo é também prevenção, é uma atitude responsável e humanizadora: ele auxilia na compreensão de quem é o ser humano, de como se desenvolve, atribuindo dessa maneira, conhecimento sobre seus comportamentos (LIMA, 2017).

Parte-se da ideia dos educandos como produtores de culturas, em que aprender se torna um ato de conhecimento da realidade concreta, ou seja, nas situações em que há a aproximação do conhecimento com a realidade. É assim que se reforça a prática da Educação Preventiva Integral, visto que, como no contexto de prevenção do abuso de drogas, por exemplo, o foco não está na substância psicoativa em si, mas sim, no educando, na sua história de vida, nas suas interações e vivências. Oportuniza-se que pelo diálogo se conheça suas demandas e potencialidades, a fim de evitar que o 
problema se instaure (ASINELLI-LUZ, 2014; LIMA, 2017; LIMA; MONTEIRO; ASINELLI-LUZ, 2019).

\begin{abstract}
A Educação Preventiva Integral possibilita auxiliar o sujeito para a superação das suas necessidades. No caso do abuso de drogas, por exemplo, é possível que seja observado, constatado, compreendido quais as angústias, anseios, medos e dificuldades e, então, atuar para a tomada de consciência da sua trajetória de vida, da perspectiva de futuro, do seu papel no mundo (LIMA; MONTREIRO; ASINELLI-LUZ, 2019, p. 14).
\end{abstract}

Desse modo, o estudo da realidade não se limita apenas à coleta de dados e fatos, mas deve perceber como o educando sente sua realidade e como busca superar a simples constatação dos fatos, sendo que esse processo passa por uma constante investigação do presente. $O$ educando, sendo inserido como agente ativo no processo de ensino, passa a ajudar a definir o seu ponto de partida por meio dos temas geradores (FREIRE, 1993; 1999).

Os temas geradores por sua vez, trabalhados não apenas em sala de aula, mas, principalmente, por educadores sociais, estão ligados à interdisciplinaridade, pois visam a uma aprendizagem global e não fragmentada. Assim, como destacado por Feitosa (1999), possibilita-se a promoção da integração do conhecimento com a transformação social, da qual originará uma palavra ou um tema gerador. É por meio dos temas geradores que se pode melhorar a compreensão da realidade, proporcionando a intervenção crítica. É necessário um teor de pluralidade de ideais sociais, culturais e políticos que devem ser selecionados de acordo com os níveis de dificuldade dos educandos. Lembrando, a seleção dos temas geradores e de suas respectivas palavras, deve ser conjunta - educador e educando - para que o processo seja democrático e de comum acordo entre todos (FREIRE, 1993).

Outro fator importante, construído por Freire (1993), e que é reforçado pela Educação Preventiva Integral, é a problematização, a busca pela superação da visão ingênua e a construção da uma visão crítica, capaz de modificar o contexto vivenciado. Essa construção da problematização decorre da consciência que os educandos adquirem de si mesmos e a transformam em outros novos aspectos e discussões. Lima (2017) destaca que a problematização entre educador e educando possibilita uma aprendizagem inovadora e libertadora, ao invés de ser mecânica, que se fortalece pela aprendizagem e requer a tomada de posições frente aos conflitos vivenciados pelos educandos e até mesmo pelos educadores.

Trata-se de uma aprendizagem diferente, abrangente, integradora, não fragmentada, promovendo uma relação de horizontalidade entre educador e educando, pois valoriza suas experiências, culturas, oralidade, ideais, fazendo um trabalho que além de ser transformador da realidade ainda possui um caráter humanístico. Nessa perspectiva, Freire $(1993,1996)$ instiga a constantes discussões e reflexões, pois rompe com a concepção de tradicionalismo na Educação, seja ela escolar ou não escolar, 
compreendendo a importância para o educando de sua história de vida. O processo educativo, na perspectiva da Educação Preventiva Integral passa a ser de "aprender a aprender" e não apenas ensinar, uma vez que o educador não se enriquece apenas mediando conhecimentos, mas, se fortalece por aprender junto ao educando, sendo essa uma experiência completamente inovadora e valiosa (LIMA, 2017).

Ao se pensar sobre a relação educador e educando, pensa-se que Paulo Freire estava muito à frente de seu tempo, pois, além de construir novos caminhos de ensino e formas de aprendizagem, possibilitava a interação por meio de materiais alternativos para a melhor percepção do educando, destacando a importância dos diversos recursos metodológicos dentro dos processos da Educação. Para Feitosa (1999), todos esses estudos e reflexões acerca da observação, reflexão, readmiração, ação, interação, fazem com que as contribuições de Paulo Freire se tornem práticas educativas, políticas, humanizadoras, pois envolvem a interação dos educandos, promovendo o estímulo tanto para a expansão da cultura, quanto para valores sociais na vida.

\section{CONSIDERAÇÕES FINAIS}

Paulo Freire assume uma posição de defesa de uma educação problematizadora e dialógica, fundamentada em princípios democráticos, no respeito às diversidades e culturas, com o rigor do conhecimento. Fala de uma educação que se contrapõe às práticas autoritárias e antidialógicas e que, por este motivo, contribui para os processos de mudanças sociais que possibilitam a ascensão do ser humano e sua dignidade como condição humana. Não se deteve na alfabetização tradicional, ele defendia um ideal que incentivava o posicionamento dos educandos nos campos sociais e políticos, voltado sempre para a sua realidade social.

Muito além de práticas de ensino e metodologias, Freire $(1993,1996,1999)$ defendia a educação humanizadora dentro de uma relação respeitosa e horizontal entre os seres humanos, principalmente entre educador e educando. Assim, a Educação Preventiva Integral foi também construída com ideias e inspirações de Paulo Freire, uma vez que busca a Educação como oportunidade de humanização, de desenvolvimento humano. Pode-se afirmar, como educação transformadora, o exercício da consciência de ser e estar no mundo.

Nessa perspectiva, o educando é o protagonista que se torna capaz de exercer seu papel dentro da sociedade, podendo ser o agente transformador de sua realidade e integrar-se diretamente como ser pensante, cultural e político.

Essas considerações acerca de uma educação transformadora, a partir da realidade do sujeito, podem contribuir efetivamente em ações impactantes em meio àqueles que estão imersos em situações de desigualdades e vulnerabilidades sociais, uma vez que a transformação acontece a partir da práxis, advinda do próprio contexto social e de convivência, bem como da consciência e da formação cidadã. A educação é a via para a transformação do sujeito, para a interação social e a busca da humanização e, juntamente a ela, a Educação Preventiva Integral possibilita auxiliar o sujeito na superação das dificuldades para satisfação de suas necessidades. 
Os educadores, por sua vez, estão diretamente ligados a seus educandos, para que juntos possam organizar as atividades desenvolvidas na sala ou nos espaços de convivência, baseando-se nos temas geradores de cunho sociológico-político inseridos em seus contextos. Assim, a prática conjunta não agirá apenas como um circuito educativo, mas também se solidificará como componente fundamental para a política, a economia, cultura e as diversas esferas da sociedade.

A Educação Preventiva Integral (ASINELLI-LUZ, 2014; LIMA, 2017; LIMA; MONTEIRO; ASINELLI-LUZ, 2019) aproxima-se da prática da Educação como Prática da Liberdade (FREIRE, 1999) por destacar que o educador e o educando precisam dialogar sobre as questões que possuem relevância em suas realidades e dentro dos grupos em que permanecem, que tematizem seus conflitos, suas demandas e suas potencialidades. Por meio dos temas geradores, eles caracterizam e norteiam o processo para a conscientização em relação ao mundo por meio de reflexões, assumindo o espaço para serem ouvidos.

Dentro do espaço da Universidade, a Educação Preventiva Integral se configurou como oportunidade de aprendizagem em uma disciplina curricular, assim como um projeto de extensão. Destaca-se que esses métodos e técnicas educativas para prevenção do abuso de drogas deu a possibilidade para que graduandos em pedagogia, psicologia, serviço social, ciências biológicas e outras áreas discutam o papel do educador e do educando dentro de suas individualidades.

As práticas humanizadoras, de compreensão do sujeito e sua história de vida, contribuem para o processo efetivo da prevenção de violências, da superação das desigualdades sociais, valorizando o ser em seu desenvolvimento e presença no mundo. Instigam ainda a problematização, no momento em que o educador motivará seus educandos a perceberem os diversos pontos de vista críticos em relação ao universo em que habitam para que possam, futuramente, atingir a tomada de consciência com totalidade.

Há o estímulo da atuação emancipadora, de transformação social, tanto na Pedagogia Escolar, quanto na Pedagogia Social. Ambas são necessárias para a promoção de diálogos e interações, visando a uma educação humanística, de qualidade e de valorização dos seres humanos na sociedade.

Artigo recebido em: 29/03/2021 Aprovado para publicação em: 29/06/2021

\section{HUMANIZATION IN PAULO FREIRE AND ITS RELATIONSHIPS WITH INTEGRAL PREVENTIVE EDUCATION}

ABSTRACT: Paulo Freire, although no longer present, is still current in many educational researches and studies, as his writings emanate hope and freedom for many educators. The values 
LIMA-BERTON, T. D. de; MONTEIRO, M. P. G.; ASINELLI-LUZ, A.

defended by him can easily be appropriate to a humanist education, which focuses on the human being, as well as Integral Preventive Education. Therefore, this study seeks to understand the main Freirian contributions to the practice of Integral Preventive Education. This is a qualitative study, of a theoretical nature, based on works by Paulo Freire $(1993,1996,1999)$ and on Integral Preventive Education (ASINELLI-LUZ, 2014; LIMA, 2017; LIMA; MONTEIRO; ASINELLI-LUZ, 2019). It is believed that humanist educational practices can contribute to the process of preventing violence and inequalities that affect human beings, since they value being and its development process as a whole.

KEYWORDS: Education. Integral Preventive Education. Humanization.

\section{HUMANIZACIÓN EN PAULO FREIRE Y SUS RELACIONES COM LA EDUCACIÓN PREVENTIVA INTEGRAL}

RESUMEN: Paulo Freire, aunque ya no está presente, todavía está al día en muchas investigaciones y estudios educativos, ya que sus escritos emanan esperanza y libertad para muchos educadores. Los valores defendidos por él pueden ser fácilmente apropiados para una educación humanista, que se centra en el ser humano, así como en la Educación Preventiva Integral. Por lo tanto, este estudio busca comprender las principales contribuciones freirianas a la práctica de la Educación Preventiva Integral. Este es un estudio teórico cualitativo, basado en trabajos de Paulo Freire (1993, 1996, 1999) y en Educación Preventiva Integral (ASINELLI-LUZ, 2014; LIMA, 2017; LIMA; MONTEIRO; ASINELLI-LUZ, 2019). Se cree que las prácticas educativas humanistas pueden contribuir al proceso de prevención de la violencia y las desigualdades que afectan a los seres humanos, ya que los seres humanos y su proceso de desarrollo en su conjunto son valorados.

PALABRAS CLAVE: Educación. Educación Preventiva Integral. Humanización.

\section{NotA}

"O presente trabalho foi realizado com apoio da Coordenação de Aperfeiçoamento de Pessoal de Nível Superior - Brasil (CAPES) - Código de Financiamento 001".

\section{REFERÊNCIAS}

ASINELLI-LUZ, Araci. Visão educacional das drogas: orientação para os pais e professores. In: ANDREOLI, Cleverson V.; TORRES, Patrícia Lupion. (Org.). Complexidade: redes e conexões do ser sustentável. Curitiba: SENAR - PARANÁ, p. 377-397, 2014. 
LIMA, Tatiane Delurdes de. O educador social e o pedagogo escolar na prevenção do abuso de drogas na adolescência. 2017. 167f. Dissertação (Mestrado em Educação) - Setor de Educação, Universidade Federal do Paraná, Curitiba, 2017.

LIMA, Tatiane Delurdes de; MONTEIRO, Michelle Popenga Geraim; ASINELLI-LUZ, Araci. O educador e a prática de educação preventiva integral. Quaderns Animació i Educació Social, v. 30, p. 1-19, 2019.

BRONFENBRENNER, Urie. Bioecologia do desenvolvimento humano: tornando os seres humanos mais humanos. Tradução: André de Carvalho Barreto. Porto Alegre: Artmed, 2011.

CUPOLILLO, Amparo Villa. Avaliação da aprendizagem escolar e o pensamento de Paulo Freire: algumas aproximações. Práxis Educativa, Ponta Grossa, PR, v. 2, n. 1, p. 51-64, jan.-jun. 2007.

FEITOSA. Sonia Couto Souza. Método Paulo Freire: princípios e práticas de uma concepção popular de educação. 156f. Dissertação (Mestrado em Filosofia da Educação), Faculdade de Educação de São Paulo, São Paulo, 1999.

FREIRE, Paulo. Educação como prática da liberdade. 23a ed. Rio de Janeiro: Paz e Terra, 1999.

FREIRE, Paulo. Pedagogia da autonomia. 1a ed. São Paulo: Paz e Terra, 1996.

FREIRE, Paulo. Pedagogia do oprimido. 23 ed. Rio de Janeiro: Paz e terra, 1987.

FREIRE, Paulo. Professora sim tia não: cartas a quem ousa ensinar. $2^{\text {a }}$ ed. São Paulo: Olho D’Água, 1993.

JOSGRILBERG, Rui. A formação do ser humano em correlação com o mundo em que vivemos. Educação \& Linguagem. v. 16, n. 2 .p. 17-41, jul.-dez. 2013.

LIROLA. María Martínez. Como promover a justiça social e a Pedagogia de Paulo Freire no Ensino universitário. Exemplos de ensino universitário de inglês. Práxis Educativa, Ponta Grossa, v. 14, n. 1, p. 34-48, jan./ abr. 2019.

MORIN, Edgar. Os sete saberes necessários à educação do futuro. São Paulo: Cortez; Brasília: UNESCO, 2000.

PAULA, Lucimara Cristina de; MELLO, Roseli Rodrigues de. As políticas de formação contínua de professores no estado de São Paulo: debatendo perspectivas de transformação a partir da pedagogia progressista freireana. Práxis Educativa, Ponta Grossa, v. 11, n. 1, p. 63-88, jan./abr. 2016.

PÉREZ GÓMEZ, Angel I. As Funções Sociais da Escola: da reprodução à reconstrução crítica do conhecimento e da experiência. In: GIMENO SACRISTÁN, José; PÉREZ GÓMEZ, Angel I. Compreender e Transformar o Ensino. 4 ed. Porto Alegre: ArtMed, 1998. 
LIMA-BERTON, T. D. de; MONTEIRO, M. P. G.; ASINELLI-LUZ, A.

SALLES, Virgínia Ostroski; FRASSON, Antonio Carlos. Educação para a paz e violência na escola: um itinerário a partir da Pedagogia da Autonomia de Paulo Freire. In: SALLES, Virgínia Ostroski; LEITE, Damaris Beraldi Godoy; FRASSON, Antonio Carlos. Formação de professores: perspectivas teóricas e práticas na ação docente. Ponta Grossa, PR: Atena Editora, 2019.

TAtiane Delurdes de Lima-berton: Doutoranda em Educação (2018-2021) e Mestre em Educação (2015-2017) pela Universidade Federal do Paraná. Especialista em Educação Integral Transformadora pela Faculdade Vicentina e Associação Gente de Bem (2015-2017). Especialista em Educação à Distância pela Faculdade Educacional da Lapa (FAEL) (2020-2021) e em Gestão Pública Municipal pela Universidade Estadual do Oeste (UNICENTRO) (2020-2022). Graduada em Tecnologia em Gestão Pública pela Universidade Estadual do Oeste (UNICENTRO) (2018-2020). Graduada em Pedagogia - Licenciatura Plena - pela Faculdade Cenecista de Campo Largo - FACECLA (Bolsista PROUNI) (2010-2014).

Orcid: https://orcid.org/0000-0001-6653-2593

E-mail: tati8lima@gmail.com

Michelle Popenga Geraim Monteiro: Doutoranda em Educação pela Universidade Federal do Paraná (2018 - 2022). Mestra em Educação (2017) pela Universidade Federal do Paraná. Especialista em Neuropedagogia pelo Instituto Rhema de Educação (2015) e graduada em Pedagogia pelo Centro Universitário Uninter (2012). Graduanda em Licenciatura em Educação Física pela UniCesumar (2021- 2025).

Orcid: https://orcid.org/0000-0003-3058-8987

E-mail: mizinhadobru@yahoo.com.br

Araci Asinelli-luz: Possui graduação em História Natural pela Pontifícia Universidade Católica do Paraná (1969), mestrado em Educação pela Universidade Federal do Paraná (1987) e doutorado em Educação pela Universidade de São Paulo (2000). Tem especialização em Ensino de Ciências, em Psicodrama Pedagógico e em Prevenção da Violência Doméstica contra criança e adolescente. Atualmente é professor associado 4 junto ao Departamento de Teoria e Prática de Ensino, Setor de Educação da Universidade Federal do Paraná.

Orcid: https://orcid.org/0000-0001-5880-0543

E-mail: araciasinelli@gmail.com

Este periódico utiliza a licença Creative Commons Attribution 3.0, para periódicos de acesso aberto (Open Archives Initiative - OAI). 